\title{
A CLINICAL STUDY OF CONGENITAL ANOMALIES OF THE DIGITS
}

\author{
Rubi Saikia ${ }^{1}$ Utpal Kumar Bordoloi ${ }^{2}$
}

1Associate Professor, Department of Anatomy, Jorhat Medical College, Jorhat, Assam.

${ }^{2}$ Associate Professor, Department of Plastic Surgery, Assam Medical College, Dibrugarh, Assam.

\section{ABSTRACT}

\section{BACKGROUND}

Congenital anomalies of the digits include malformations like Polydactyly, Syndactyly, Brachydactyly, Macrodactyly, Cleft hand and foot (Lobster claw deformity), Constriction ring, Polysyndactyly, Thumb aplasia (Ectrodactyly) or Hypoplasia, etc. Among these, polydactyly is the commonest congenital deformity, presenting with a range of defects from minor soft tissue duplication to major bony abnormalities.

Aim- The present study was aimed at studying the incidence of various types of anomalies of the digits in Dibrugarh district of Assam, India.

\section{MATERIALS AND METHODS}

This is a descriptive study. The study was carried out in patients attending the Plastic Surgery OPD at Assam Medical College \& Hospital and at Srishti Hospitals \& Research Centre, Dibrugarh, Assam from July 2014 to July 2017. We did an analysis of a total of 3850 patients for the presence of any congenital anomaly of digits. Of these, $2116(54.96 \%)$ were male and 1734 (45.04\%) were female. Those cases with congenital malformations of the digits were further investigated in detail for family history, maternal drug history during pregnancy, history of exposure to radiation during pregnancy, consanguinity, and associated congenital anomalies. The cases were photographed for record.

\section{RESULTS}

Among the 3850 patients included in the study, only $35(0.91 \%)$ presented with noticeable anomalies of the fingers \& toes. Of these, the commonest was polydactyly in $20(57.14 \%)$ cases followed by syndactyly in $8(22.56 \%)$ cases. We found macrodactyly (Foot) in $2(5.71 \%)$ cases. $1(2.86 \%)$ case each of polysyndactyly, brachydactyly, thumb aplasia, amniotic band amputation and lobster claw hand was found.

\section{CONCLUSION}

Congenital anomalies have always been a source of social stigma. Most of these anomalies can be corrected surgically.

\section{KEYWORDS}

Congenital Anomaly, Polydactyly, Syndactyly, Macrodactyly, Cleft Hand, Aplasia, Hypoplasia.

HOW TO CITE THIS ARTICLE: Saikia R, Bordoloi UK. A clinical study of congenital anomalies of the digits. J. Evolution Med. Dent. Sci. 2017;6(93):6761-6765, D0I: 10.14260/jemds/2017/1464

\section{BACKGROUND}

The stigma of a congenital malformation has always been present in varied forms. Early reference to limb anomalies are found in the Old Testament of the Bible: Goliath was a member of a band of giants with polydactyly.(1) A six-fingered hand was so common in one Arabian tribe, the Hyabites, that a child with 5 digits was considered abnormal and subsequently sacrificed.(2) Extra digits in England were considered a sign of royalty, owing to the frequent appearance of polydactyly in the royal line since Mary, the Queen of Scots.(3) The parents may be initially devastated by guilt when an imperfection is seen in their otherwise normal child.

'Financial or Other Competing Interest': None.

Submission 24-10-2017, Peer Review 20-11-2017,

Acceptance 27-11-2017, Published 11-12-2017.

Corresponding Author:

Utpal Kumar Bordoloi,

Associate Professor,

Department of Plastic Surgery,

Assam Medical College,

Dibrugarh-786002,

Assam.

E-mail: utpalbordoloi50@gmail.com

DOI: $10.14260 /$ jemds $/ 2017 / 1464$

\section{(c) $(1)$}

They must be counseled honestly and informed clearly about potentials from the time of initial consultation. When a complex deformity exists, they should not be given unrealistic expectations about the result.

Majority of congenital deformities of the digits can be corrected by surgery. According to literature, the most common congenital limb malformation is polydactyly which is characterised by the occurrence of more than 5 digits in hand or foot. Polydactyly can vary from an unnoticeable rudimentary finger or toe to fully developed extra digit.(4),(5) Syndactyly is the webbing or fusing together of two or more fingers or toes. It also exhibits a large degree of variation. Digits can be partially fused or fused along their entire length. The fusion can be simple with the digits connected only by skin or it can be complicated with shared bones, nerves, vessels or nails. Polydactyly and syndactyly can occur simultaneously when extra digits are fused. This condition is known as polysyndactyly.

Hand deformities occur due to errors in the process of foetal development. They can occur by themselves as isolated conditions or in conjunction with other symptoms as one aspect of multi-symptom diseases like Apert syndrome, Meckel syndrome, Poland syndrome, VACTERL association, etc. 


\section{Embryology}

The limb buds appear as outpocketings from the ventrolateral body wall at the end of fourth week of development. The forelimb bud appears first followed by the hind limb buds 1-2 days later.

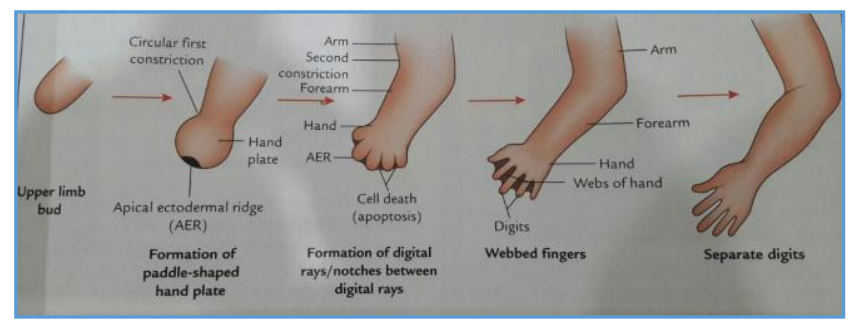

Figure 1. Stages in the Development of Upper Limb (Courtesy[7])

The ectoderm at the tip of the limb bud thickens to form the apical ectodermal ridge (AER). During the $6^{\text {th }}$ week of development, the terminal part of the limb buds become flattened to form the hand and foot plates. These are separated from the rest of the limb bud by a circular constriction. The expanded plate exhibits five longitudinal mesodermal condensations called the digital rays. Later, a second constriction divides the rest of the limb into two segments. Digits are formed in the hand and foot plate following programmed cell death (apoptosis) in the apical ectodermal ridge as shown. Limb outgrowth is initiated by FGF (fibroblast growth factor) 10, secreted by the lateral plate mesoderm in the limb forming regions. Once outgrowth is initiated, the AER (apical ectodermal ridge) is induced by bone morphogenetic proteins and restricted in its location by the gene Radical fringe expressed in dorsal ectoderm. In turn, this expression induces SER2 (a homologue of Drosophila serrate) in cells destined to form the apical ectodermal ridge. After the ridge is established, it expresses FGF4 \& FGF8 to maintain the progress zone. Anteroposterior patterning of the limb is controlled by cells in the zone of polarising activity (ZPA) at the posterior border. These cells produce retinoic acid (vitamin A), which initiates expression of sonic hedgehog (SHH) that regulates the anteroposterior axis. The dorsoventral limb axis is directed by WNT7a, which is expressed in the dorsal ectoderm. This gene induces expression of the transcription factor LMX1 in the dorsal mesenchyme, specifying these cells as dorsal. Bone type \& shape are regulated by HOX genes.(6),(7)

\section{MATERIALS AND METHODS}

This is a descriptive study. We carried out the present study in 3850 OPD cases who attended the Plastic Surgery OPD in Assam Medical College \& Hospital and OPD at Srishti Hospitals \& Research Centre at Dibrugarh, Assam. Among these only 35 cases presented with deformities of the digits. Each of these 35 cases were examined in detail for any other associated deformity. We also obtained the mother's history of drug intake, alcohol intake and exposure to radiation during pregnancy. Special attention was given on the family history of congenital malformations and consanguineous marriage.

\section{Inclusion and Exclusion Criteria}

Patients who had a deformity as a result of an accident or burn were excluded from this study. Only those with inborn congenital malformations of hands and feet were considered for the study.

\section{RESULTS}

The most common congenital anomaly found in our study was polydactyly (20 cases), followed by syndactyly (8 cases). $3(13.63 \%)$ of the 20 cases of polydactyly were bilateral postaxial (ulnar) polydactyly.

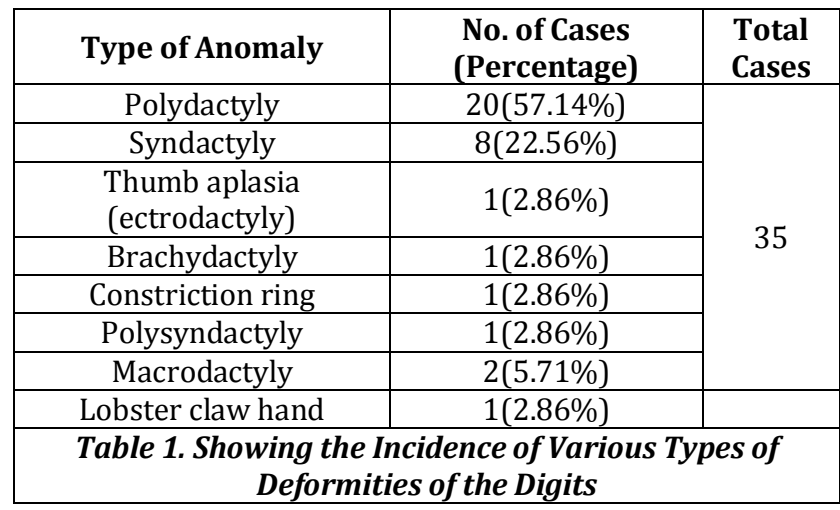

\begin{tabular}{|c|c|c|}
\hline \multicolumn{2}{|c|}{ Polydactyly } & \multirow{2}{*}{ Total } \\
\hline Postaxial type & Preaxial type & \\
\hline $13(65 \%)$ & $7(35 \%)$ & $20(57.14 \%)$ \\
\hline \multicolumn{2}{|c|}{ Table 2. Showing the Types of Polydactyly } \\
\hline
\end{tabular}

\begin{tabular}{|c|c|c|}
\hline \multicolumn{2}{|c|}{ Syndactyly } & \multirow{2}{*}{ TOTAL } \\
\hline Unilateral & Bilateral & \\
\hline 6 & 2 & 8 \\
\hline \multicolumn{2}{|c|}{ Table 3. Showing the Occurrence of Syndactyly } \\
\hline
\end{tabular}

\begin{tabular}{|c|c|c|}
\hline \multicolumn{2}{|c|}{ Syndactyly } & \multirow{2}{*}{ Total } \\
\hline Complete & Incomplete & \\
\hline 6 & 2 & 8 \\
\hline \multicolumn{2}{|c|}{ Table 4. Showing the Type of Syndactyly } \\
\hline
\end{tabular}

\section{DISCUSSION}

Congenital anomalies of the limbs are not uncommon. Review of literature suggests polydactyly and syndactyly as the most common deformities of the limbs. In a systematic study of limb anomalies, conducted in Iowa for a period of 15 years, polydactyly and syndactyly were found to be the common entity. Geographic differences highlight tremendous variation. Polydactyly is two to three times more common in Asian countries and in certain well-studied regions within the United States where Negro and American Indian groups predominate (Flatt, 1977). Absence deformities including constriction rings occur much less frequently, with an incidence of one in 2000 to 3000 live births (Goldberg and Bartoshesky, 1985). The relative incidence of individual anomalies varies with the population being studied. The birth of a child is a long awaited, often eagerly awaited, event. After parents and family recover from the initial shock of a congenital imperfection, they approach the surgeon for a solution. Initial evaluation by a surgeon should consist of - a complete family history, a thorough pregnancy history and postnatal growth and development. All minor and major abnormalities should be recorded. Hand anomalies are 
usually classified as minor. When three or more minor anomalies exist in a single patient, there is a $90 \%$ chance that a major abnormality will also be found.(8)

Polydactyly or duplication is the most common congenital anomaly of the limbs. All portions of the hand may be involved. Total duplication of the hand and forearm or "ulnar dimelia" is so rare that it almost constitutes a medical curiosity. On the preaxial side of the limb bud, thumb duplication occurs in a great variation. Duplication of the index, middle and ring fingers are much less common. Postaxial polydactyly is the most common variety and the single most common congenital anomaly seen in most cultures. It is eleven times more common in the black population whereas preaxial polydactyly was equally common in both races.(9) A large number of anatomic varieties of preaxial polydactyly indicate its genetic heterogenicity.

Duplicated digits have been well documented in all races throughout the world. The Bible describes polydactylous giants in $11^{\text {th }}$ century B.C. The trait was so common in some inbred tribes of Hyamites that a child born without a hexadactylous hand was thought to be illegitimate. In England, polydactyly was thought to be a sign of royalty but in some other societies, this anomaly was thought to bear a sign of inferiority, and affected infants were killed. Polydactyly is thought to be the result of an excess longitudinal segmentation that probably represents an increased folding of apical ectodermal ridge. The degree of development of extra portions varies enormously from a small, loosely attached soft tissue to a fully developed functional finger. Polydactyly can occur in isolation or as a part of a syndrome. The incidence is as high as 1 per 300 in American Negros and American Indians and as low as 1 per 3000 in Caucasians.(10) (11) In the present study, we found the incidence of polydactyly to be $57.14 \%$. Our findings are similar to the findings of Bilodi AKS \& Gangadhar MR(12) who found it to be $67.5 \%$ in their study.

Syndactyly is constantly one of the two most common congenital anomalies of the digits seen in different cultures. It is frequently seen in association with other malformations. It occurs due to failure of digital rays to separate from one another by a process of programmed cell death (apoptosis) during the seventh to eighth week of intrauterine life. The true incidence of syndactyly varies from one part of the world to another but it is seen in approximately one per 2000 live births. Half the cases are bilateral and males are more commonly affected.(13) Syndactyly is most commonly seen in the $3^{\text {rd }}$ web space in the hand and $2^{\text {nd }}$ web space in the foot. The first web space in hand is least frequently affected because the thumb separates from the rest of the hand at a much earlier stage. Syndactyly can be inherited or can occur sporadically. When inherited, it is transmitted in an autosomal dominant pattern with variable expressivity and incomplete penetrance. Syndactyly is clinically classified according to (a) the degree of webbing along the length of the digit (complete versus incomplete) and (b) presence or absence of a bone union or other skeletal abnormality (simple versus complex) (Flatt, 1977). In the present study, the incidence rate of syndactyly was found to be $22.56 \%$. Bilodi AKS found it to be $27.5 \%$ in their study. However, syndactyly is one of the most treatable defects in a child.
Depending on the location and degree of enlargement, overgrowth has been called by many names. The term macrodactyly (Gr. Macros= large; dactylos = digit) has been used most frequently to describe an overgrowth of a finger although the malformation is not restricted solely to digits (Flatt, 1977). Many prefer the term 'digital gigantism' because it encompasses enlargement of all tissue elements, including the skeleton.(14) Many of these conditions have been called hamartomas (Gr. Hamartia $=$ to $\sin$ ) as malformed tissue that grow locally. As a group, overgrowth or gigantism occupy a very small portion of congenital hand deformities, but when present, they challenge even the most accomplished hand surgeon. Macrodactyly could affect any of the digits. It could be due to nerve-oriented lipofibromatosis or neurofibromatosis or hyperostosis or hemihypertrophy.(15) In the present study, we found macrodactyly in $2(5.71 \%)$ cases. Both the cases were females whose $2^{\text {nd }}$ toe was involved (one right side \& one left side).

Numerous terms like annular bands, constriction rings or grooves, annular defects, intrauterine or foetal amputation have been used to describe congenital constriction ring syndrome. The aetiology of constriction rings has been the subject of great interest for centuries. It is believed that early rupture of amnion produces fibrous bands that become entangled with foetal parts such as limbs. The resulting defects primarily consists of missing toes or fingers, clubbed feet, severe constriction rings around other body parts and occasionally an amputation. The depth of the groove due to a tight constriction ring may vary from a mild deficiency of subcutaneous tissue to a deep circumferential indentation that may interrupt veins, lymphatics, tendons and even nerves.(16)(17) In the present study, we found a single case of amputation of the fingers by amniotic bands.

Absence of digits or metacarpals within the central portion of hand constitutes the cleft hand. Here, the radius and ulna are present. Cleft hand is classified into two typesTypical and Atypical. Atypical cleft hands have historically been called 'ectrodactyly' or 'symbrachydactyly'. Typical type of cleft hand has a defect of variable depth within the central portion of hand. In severe forms, syndactyly between the thumb-index and ring-small rays may be present and the long ray may be completely absent. More extensive involvement may result in complete absence of the index and long rays. In atypical type of cleft hand, the central rays either are missing or have deficient components. Phalanges are commonly absent but a portion of metacarpal is present. The hand is occasionally hypoplastic and the thumb and fifth rays are the best developed digits in the entire hand. Lobster claw hand has been used to describe an atypical cleft hand with border rays (thumb and small), a large intervening cleft and often, nubbins representing hypoplastic digits.(18) In the present study, we found a case with right-sided lobster claw hand. The left hand of the baby was normal, including the lower limbs.

Thumb deformity imposes a proportionally greater functional liability than does deformity of any other digits. Thumb agenesis or severe hypoplasia or severe first web space syndactyly, etc. renders the hand considerably more primitive. Congenital absence of thumb usually consists of anomalies of all first ray elements, including scaphoid, trapezium and phalangeal elements. The hypoplastic thumb is generally attached to the radial side of the hand. In spite of 
thumb aplasia or marked hypoplasia, children may use their hands skilfully, even when lacking pulp to pulp prehension. Normally, it is to the index finger the child turns. A rudimentary thumb precariously attached should be deleted in early infancy before emotional attachment occurs. Thumb reconstruction in the four-fingered hand is rarely resisted by parents, especially when the absence is bilateral. Reconstructive surgery of the thumb should be carried out in early infancy, before the beginning of school.(19) In the present study, we found a case who had aplasia of the right thumb and hypoplasia with severe first web space syndactyly of the left hand.

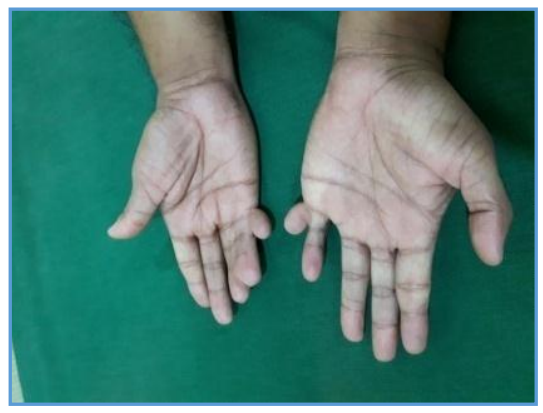

Photograph 1. Right-sided Polysyndactyly \& Left-sided Postaxial Polydactyly

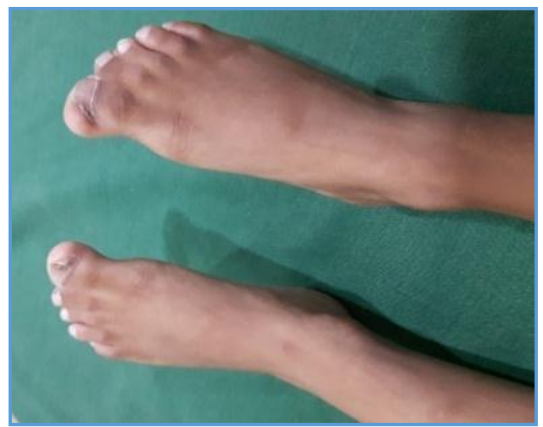

Photograph 2. Syndactyly (complete) of Feet

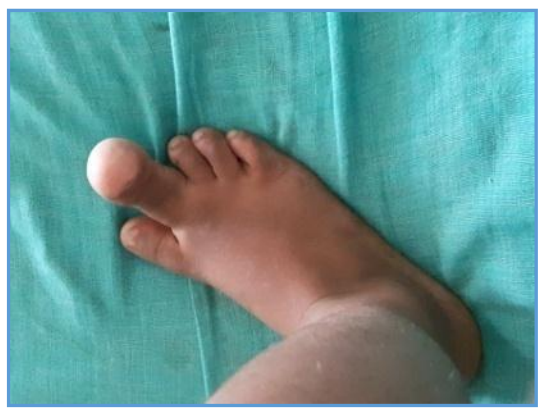

Photograph 3. Macrodactyly

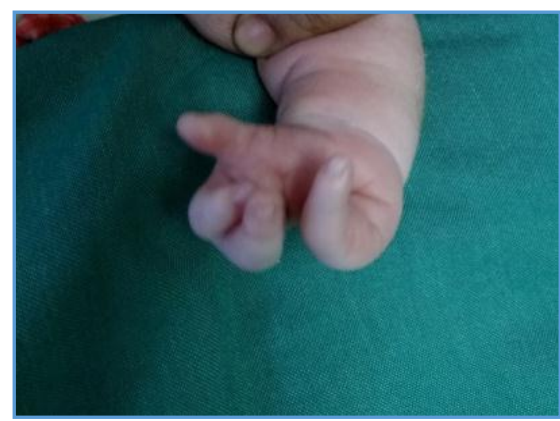

Photograph 4. Lobster Claw hand

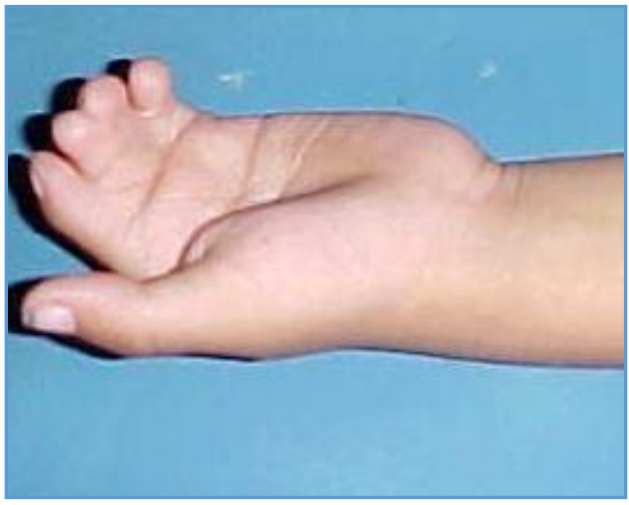

Photograph 5. Syndactyly Involving Medial 4 Digits

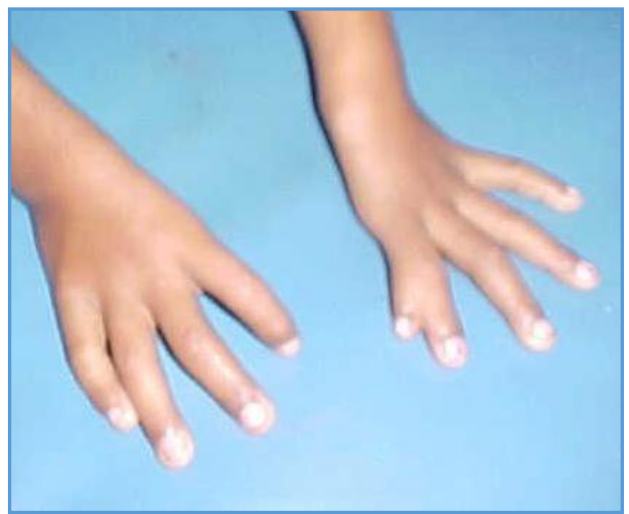

Photograph 6. Thumb Aplasia

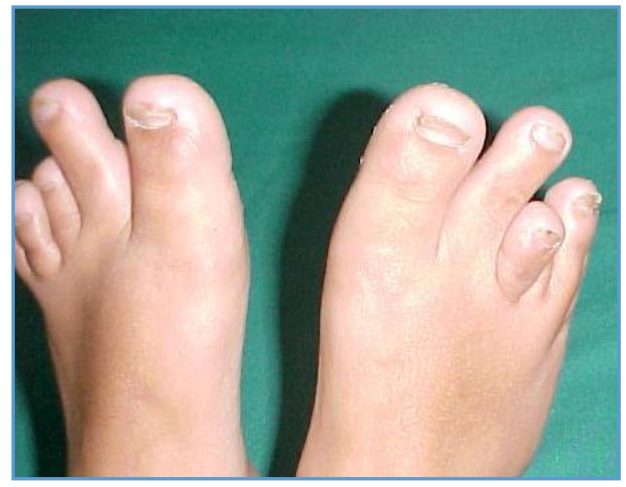

Photograph 7. Brachydactyly Band Amputation

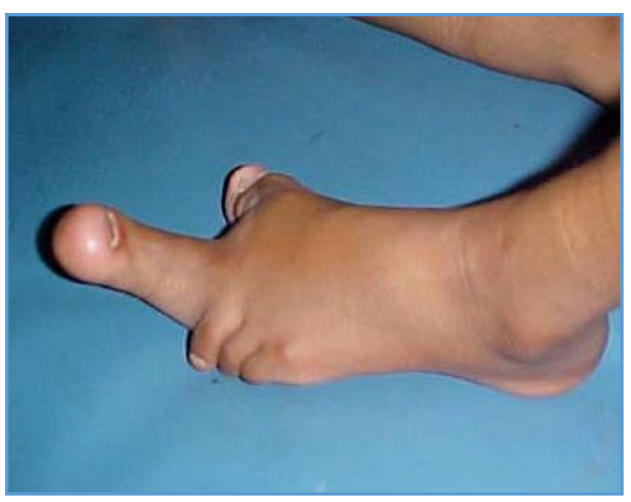

Photograph 8. Macrodactyly 


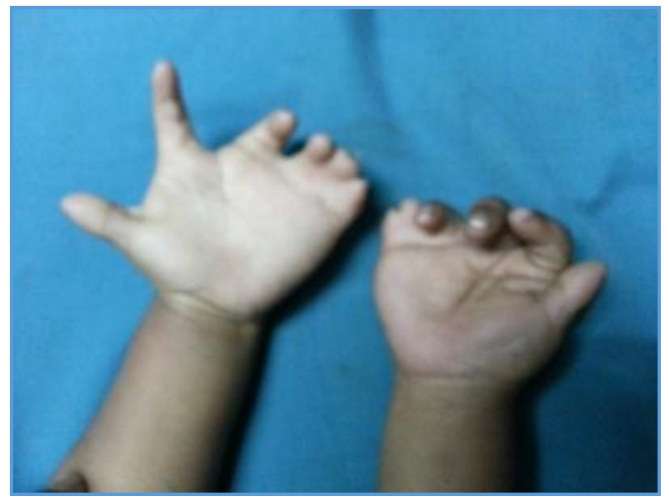

Photograph 9. Amniotic

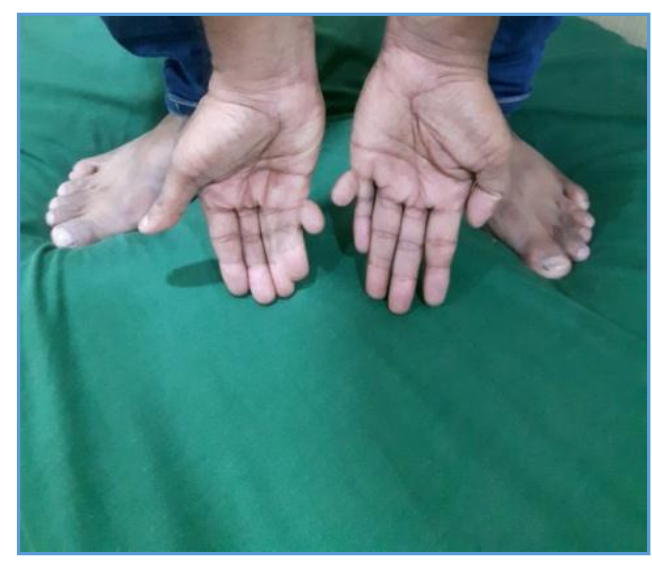

Photograph 10. Polysyndactyly of Hand with Syndactyly of Feet

\section{CONCLUSION}

Visible congenital malformations of the hand causes dismay to the entire family. Since the body concept usually begins to form around the age of 4-5 years, it would be ideal to plan the surgery before the child enters school and becomes psychologically traumatised by ridicule of peers. The prognosis for isolated polydactyly and syndactyly is excellent.

\section{REFERENCES}

[1] Tamtamy SA, McKusick VA. The genetics of hand malformations. Birth Defects Orig Artic Ser 1978;14(3):i-xviii, 1-619.

[2] Bionet E. Polydactylie et atavisme. Rev Med (Paris) 1898;18:316-28.

[3] Flatt AE. Cleft hand and central defects. In: The care of congenital hand anomalies. St. Louis: C.V. Mosby 1977:265-85.
[4] Mallen GW. The frequency of birth defects. In: Fishbein M. edr. Birth defects. Philadelphia: JB Lippincott Company, 1963.

[5] Goldberg MJ, Bartoshesky LE. Congenital hand anomaly: etiology and associated malformations. Hand Clin 1985;1(3):405-15.

[6] Sadler TW. Langman's medical embryology. $11^{\text {th }}$ edn. Philadelphia: Lippincott Williams and Wilkins 2010:134-9.

[7] Vishram S. Textbook of clinical embryology. 2nd edn. Elsevier 2012:96-8.

[8] Holmes LB. Congenital malformations. In: Cloherty JP, Stack AR. eds. Manual of neonatal care. Boston: Little Brown and Company, 1980.

[9] Upton J. Congenital anomalies of the hand and forearm. In: McCarthy JG. edr. Plastic surgery. The Hand. Vol 8. Part 2. Philadelphia: WB Saunders 1990:5213-398.

[10] Woolf CM, Myrianthopoulos NC. Polydactyly in American Negroes \& Whites. Am J Hum Genet 1973;25(4):397-404.

[11] Nathan PA, Kensington RC. Crossed polydactyly. Case report and review of the literature. J Bone \& Joint Surg 1975;57(6):847-9.

[12] Bilodi AKS, Gangadhar MR. Study of various types of congenital anomalies of hand. IJIMS 2014;1(3):50-60.

[13] Kelikian H. Congenital deformities of the hand and forearm. Philadelphia: WB Saunders Company, 1974.

[14] Edgerton MT, Tuerk DB. Macrodactyly (digital gigantism): its nature \& treatment. In: Littler JW, Cramer LM, Smith JW. eds. Symposium on reconstructive hand surgery. Vol 9. St. Louis: CV Mosby Company, 1974.

[15] Barsky AJ. Macrodactyly. J Bone Joint Surg 1967;49(7):1255-66.

[16] Casaubon JN. Congenital band about the pelvis. Plast Reconstr Surg 1983;71(1):120-2.

[17] Farmer AW. Congenital elephantiasis associated with constriction by anomalous bands. J Bone Joint Surg 1948;30B:606.

[18] Barsky AJ. Congenital anomalies of the hand and their surgical treatment. Springfield, Illinois: Charles C. Thomas Company, 1958.

[19] McGraw MB. The neuromuscular maturation of the human infant. New York: Hafner Publishing 1943:93101.

[20] Knorr NJ, Edgerton MT, Barbarie M. Psychological factors in reconstruction of the ear. St. Louis: Mosby Company 1974: p. 187. 